\title{
Pterygium Excision with Sutureless, Glueless Conjunctival Autograft
}

\section{Sachit Dhakal, Kamala Thapa and Niranjan Sharan}

Department of Ophthalmology, Nepalese Army Institute of Health Sciences, Shree Birendra Hospital, Chhauni, Kathmandu, Nepal

ABSTRACT
Introduction: Pterygium is a common condition and various surgical techniques have been described for its
excision, of which autografting is seen to have very less recurrence. Graft fixation with fibrin glue is gaining
popularity, but autologous serum might be a cheaper alternative. This study was planned to explore the
efficacy of autologous serum as a stabilising agent for graft surgery in pterygium.
Methods: The hospital data of patients who underwent pterygium surgery with autografting using autologous
serum in the Department of Ophthalmology of Shree Birendra Hospital, Chhauni, Kathmandu, Nepal between
Oct 2015 to Sept 2017 were retrospectively analysed. The graft stability post-surgery was studied.
Results: 46 eyes of 46 patients underwent pterygium surgery with autograft using autologous serum. The
male to female ratio was 1.08:1, and the mean age was 45 years. All the pterygium were nasal sided. Post-
operatively the graft was stable in all of the cases.
Conclusions: Autologous serum is a good stabilising agent for graft surgery in pterygium.
Key words: Autologous serum; Glueless; Pterygium excision; Sutureless

Correspondence: Sachit Dhakal, Department of Ophthalmology, Shree Birendra Hospital, Nepalese Army Institute of Health Sciences, Sanobharyang, Kathmandu, Nepal. E-mail: sachit.dhakal@naihs.edu.np

DOI: $10.3126 / \mathrm{mj}$ sbh.v20i1.29999

Submitted on: 2020-07-12

Accepted on: 2021-01-09

This work is licensed under creative common license:

http://creativecommons.org/licenses/by-nc-nd/4.0/ (C) MJSBH 2020 


\section{INTRODUCTION}

Pterygium is a common condition seen mostly in the adult population, exposed to a hot and dry climate, and UV rays. ${ }^{1}$ It is a fibrovascular growth encroaching into the cornea. The most common complaints are redness, foreign body sensation, dryness, and refractive error due to induced astigmatism. ${ }^{2}$ Sometimes the pterygium crosses over the visual axis leading to significant visual disturbances. Pterygium excision is done to relieve the symptoms as well as for cosmetic purposes.

There are various techniques described for the pterygium excision. The bare sclera technique involves leaving the sclera exposed after dissection of the pterygium, but it has been found to have a high rate of recurrence. ${ }^{1}$ Conjunctival autograft and amniotic membrane graft with or without the use of mitomycin $\mathrm{C}$ has been shown to have a very fewer recurrence rate. ${ }^{3,4}$ The conjunctival autograft needs to be stabilized by sutures, which tends to take more time during surgery and also leads to post-op discomfort, though this has less recurrence rate. Recently, autografting with fibrin glue as a graft stabilizing agent has been used, ${ }^{5}$ but it adds up to the cost of surgery, and also there is a risk of infection transmission. ${ }^{6}$ Due to this, to minimize the recurrence rate as well as to cut down on the cost of surgery and improve patient comfort postop, conjunctival autograft without the use of suture or glue has been recently tried, though the graft stability post-op might be at risk. This research was done to check the graft stability after glueless and sutureless conjunctival autograft pterygium excision.

\section{METHODS}

Pterygium surgeries done during October 2015 to September 2017 in Shree Birendra Hospital, Chhauni, Kathmandu, Nepal were included in the study. Ethical clearance from the Institution Review Board was taken prior to the study. All the surgeries were performed by a single surgeon (SD) and the technique in all the cases were similar. A total of 46 patients were operated on during that period in our institute. Preoperatively, patients were examined in the Ophthalmology OPD using slit-lamp. All cases were of primary, atrophic (non-progressive) pterygium. Informed written consent was taken from all the patients undergoing surgery and blood sugar and bleeding parameters were tested as a preop investigation.

Surgical technique: All cases were done under a peribulbar block. After cleaning and draping, the conjunctiva over the pterygia was lifted by injecting normal saline sub-conjunctival. A conjunctival incision was given concentric to the limbus and conjunctiva dissected from the pterygia mass followed by dissection of pterygia mass from the sclera tissue below. Pterygia mass was cut 4 $\mathrm{mm}$ away from the limbus, reflected towards the cornea, and peeled from the cornea by holding with forceps. Any pterygia tissue on the cornea was scraped using a keratome. The bare scleral area was measured using caliper on all the sides and $1 \mathrm{~mm}$ larger marking was made in the superior bulbar conjunctiva of the same eye and conjunctival autograft was harvested. The bare sclera area was slightly scraped with cotton buds to make the blood ooze slightly to have a thin film of blood, and in cases where this didn't work, sclera was scraped with a keratome knife. The harvested graft was placed over the bare sclera with a thin film of blood as an adhesive agent, aligning the limbal side of the graft with the limbus. The graft was tucked underneath the conjunctiva on the three sides. A waiting time of at least $30 \mathrm{sec}$ was practiced before removing the lid wire speculum, taking the extra precaution of not disturbing the graft. Before applying the eye pad, a drop of antibiotic was instilled and the graft position checked again.

Postoperative period: All cases were called on day one and day seven. The graft was evaluated for loss, dislocation, or retraction. Post-op antibiotics and steroid eye drops were prescribed for a total of six weeks, during which time, steroid eye drops were gradually tapered every week and stopped.

\section{RESULTS}

A total of 46 eyes of 46 patients underwent pterygium excision with glueless, sutureless

Table 1. The table shows the sex distribution of the patient and their percentage

\begin{tabular}{|l|r|r}
\hline Sex & Number & \multicolumn{2}{c}{ Percentage } \\
\hline Male & 24 & $52.17 \%$ \\
\hline Female & 22 & $47.83 \%$ \\
\hline
\end{tabular}




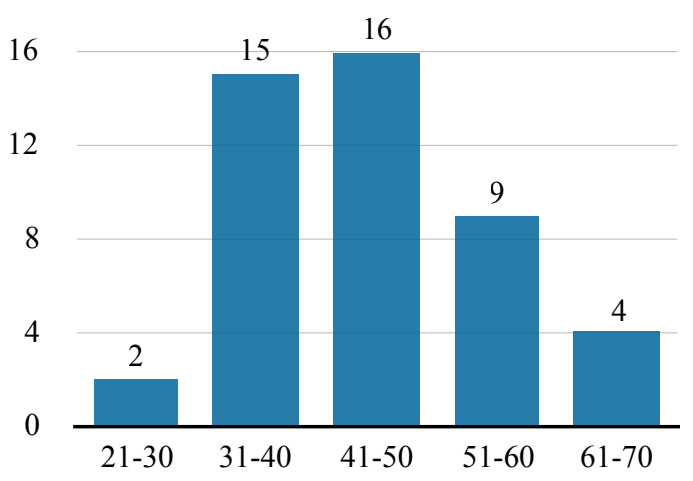

Figure 1. Age-wise distribution of the patients included in the surgery

conjunctival autografting surgery. Sex ratio was found to be close to equal with 24 male and 22 female patients with a sex ratio of male:female as 1.08:1 as shown in table 1 . Twenty four eyes were right eye and 22 were left eye. All pterygia were nasal one. The age range of patients who underwent pterygium excision was between the third to seventh decades of life (25 - 68 years) with the mean age of 45 years ( $\mathrm{SD} \pm 10$ years).

Table 2 shows the outcome of all the patients who underwent sutureless, glueless pterygium surgery. During the post-operative examination on day 1 and day 7, grafts of all the patients were found to be intact, with absence of graft retraction as well. Patients complained of mild to no pain and very minimal discomfort.

\section{DISCUSSION}

Pterygium is a fairly common condition seen in our part of the world due to its geographic location. Nepal, being an agricultural-based economy, the majority of the workforce spends their productive time outdoor which leads to excessive exposure to UV light as well as hot and dry climate, especially in rural areas. ${ }^{7}$ This might be the reason for the young population to develop this degenerative condition as seen in our study where the youngest patient was 25 years old. The only definitive treatment of pterygia is excision and various technique has been utilised, mostly to prevent a recurrence. At present, pterygium excision with autografting has been shown to have the least rate of recurrences. ${ }^{3,4}$ There are various methods used for anchoring the harvested autograft, the most common being sutures (Vicryl, Nylon). Recently,
Table 2. Outcome of pterygium surgery

\begin{tabular}{l|l|r}
\hline Sugery & Outcome & Number \\
\hline Graft Dislocation & Present & 0 \\
\cline { 2 - 3 } Graft Retraction & Absent & 46 \\
& Present & 0 \\
\cline { 2 - 3 } & Absent & 46 \\
\hline
\end{tabular}

the non-suturing technique using fibrin glue is gaining popularity. The use of any extra material during the surgery only adds to the financial burden and its related complications.

In our cohort of 46 cases, we were able to achieve graft stability in all cases on day 1 as well as day 7 by using the autologous serum. The use of fibrin glue for graft adhesion has been gaining popularity due to short surgical time and less post-op discomfort, but it adds up to the surgical cost and there are also added risks of transmission of infections. ${ }^{6}$ Autologous serum as a graft stabilising agent has all the benefits of fibrin glue, and added advantages of no extra cost and no chance of transmission of infections. There have been studies that have shown graft stability of $100 \%$ in autologous method $^{8,9}$ whereas others ${ }^{10,11}$ have shown graft dislocation rate of 24 to $40 \%$ in autologous group, and it was seen within the first 7 days. ${ }^{10}$ Some authors have used autologous serum extract from blood drawn from the patients, ${ }^{11}$ but our technique of using thin blood film over sclera cuts down on extra procedure. Hence, this method of pterygium surgery is beneficial in our setting where patients are not that affording.

Our study does have certain limitations. It was a retrospective data based study. The study being conducted at the single centre and by the single surgeon with very small sample size, the results may not be applicable to the entire population. We had included only primary, non-progressive type of pterygium for the surgery and outcome in the progressive type of pterygium as well as recurrent pterygium has not been evaluated. As the outcome measure was only to see the graft stability by using the autologous serum on post-operative day 1 and day 7 , any graft issues after day 7 have not been evaluated. Further, this study does not consider any recurrence rate in using this type of surgical technique. 


\section{CONCLUSIONS}

The sutureless and glue-less approach of anchoring the graft with the utilisation of oozed serum from the scleral bed gives a promising result. It has further benefits of a less financial burden to the patients as well as to the institutions too. However, our findings need to be corroborated in further larger studies in the future.

To cite this article: Dhakal S, Thapa K, Gurung A, Rajkarnikar S, Shrestha R, Sharan N. Pterygium Excision with Sutureless, Glueless Conjunctival Autograft. MJSBH. 2021;20(1):46-9.

Conflict of Interest: None declared

\section{REFERENCES}

1. Bowling B. Kanski's clinical ophthalmology. [Edinburgh]: Elsevier; 2016.

2. Lin A, Stern G. Correlation between pterygium size and induced corneal astigmatism. Cornea. 1998;17(1):28-30. DOI: $10.1097 / 00003226-199801000-00005$.

3. Ram A, P S, G A. Comparative Study Of Recurrence Rate Of Pterygium Excision With Bare Sclera Technique And Conjunctival Autograft In Nalagonda Dist. J Evol Med Dent Sci. 2013;2(18):3025-30. DOI: 10.14260/jemds/654

4. Avisar R, Gaton DD, Loya N, Appel I, Weinberger D. Intraoperative mitomycin C $0.02 \%$ for pterygium: effect of duration of application on recurrence rate. Cornea. 2002;22(2):102-4. DOI: 10.1097/00003226-200303000-00003. PMID: 12605040.

5. Bahar I, Weinberger D, Dan G, Avisar R. Pterygium surgery: fibrin glue versus Vicryl sutures for conjunctival closure. Cornea. 2006;25(10):1168-72. DOI: 10.1097/01.ico.0000240087.32922.ee.

6. Panda A, Kumar S, Kumar A, Bansal R, Bhartiya S. Fibrin glue in ophthalmology. Indian J Ophthalmol. 2009;57(5):371-9. DOI: 10.4103/0301-4738.55079.

7. Manandhar L, Rai S, Gurung S, Shrestha K, Godar M, Hirachan A, et al. Prevalence of pterygium and outcome of pterygium surgery in hilly western Nepal. J Lumbini Med Coll. 2017;5(1):18. DOI: 10.22502/jlmc.v5i1.120

8. Alam J, Bhattacharjya H, Ray A, Das M. Pterygium Excision With Sutureless Glueless Conjunctival Autografting: An Experience Of 30 Cases. J Evol Med Dent Sci. 2014;3(12):3024-9. DOI: 10.14260/jemds/2014/2239

9. de Wit D, Athanasiadis I, Sharma A, Moore J. Sutureless and glue-free conjunctival autograft in pterygium surgery: a case series. Eye (Lond). 2010;24(9):1474-7. DOI: 10.1038/eye.2010.75.

10. Nadarajah G, Ratnalingam VH, Mohd Isa H. Autologous Blood Versus Fibrin Glue in Pterygium Excision With Conjunctival Autograft Surgery. Cornea. 2017;36(4):452-6. DOI: 10.1097/ICO.0000000000001106.

11. Rafe A, Naeem S, Munawar T. Fibrin Glue Versus Autologous Serum for Conjunctival Autograft Fixation in Pterygium Surgery. Pak J Ophthalmol. 2020;36(1). DOI: 10.36351/pjo.v36i1.1007 